\section{A (Cliniral âlerture}

on

\section{RESECTION OF THE CAECLII FOR CANCER OF THE ILEO-CAECAL VALVE.}

Delivered at St. Bartholomew's Hospital.

BY HARRISON CRIPPS, F.R.C.S.,

SENIOR SURGEON.

Gentlemen,--In a recent lecture I gave you a short account of the symptoms and treatment of rectal cancer. To.day I have a good opportunity of saying something about the same disease in the opposite end of the colon for on the table before you are three caeca resected for cancer of the ileo-caecal valve. All the operations were done during the same week, which shows that the disease is not uncommon.

For the following notes I am indebted to my housesurgeon, Mr. Hoskyn.

Case I.

W. B., aged 63, clerk. Admitted into the hospital November, 1908, complaining of pain in the abdomen since September. He has had two or three attacks of diarrhoea, but after these has gone some days without any motion. The diarrhoea was preceded and accompanied by violent vomiting. He has never passed any blood or mucus. $\mathrm{He}$ is a sallow-looking man with a large and full abdomen. Has lost weight recently. On the first examination no tumour could be nation no tumour could be A tays later a tumour the size of an egg was detected 1 in. above and to the right of the umbilicus. The tumour was very mobile. Some days it could be easily felt, at other times the most careful palpation failed to detect it. It seemed to disappear under the ribs.

Operation.-November 16th. A 6 in. incision along the outer border of the right rectus. On opening the abdomen a small amount of free fluid escaped. On introducing the hand a tumour was at once felt, freely movsble, and it could be pushed several inches in any direction. The edge of the tum tum was adherent to it. It proved to be a hard malignant adenoid growth, spread ing like a thick ring all round the valve and projecting into the caecum. The growth extended up to but not through the peritoneal coat. The caecum was excised, with about 2 in. of the ileum on one side and the same amount of the ascending colon on the other. An end-to-end anastomosis was made, great care being taken to unite the mesenteric attachments. The patient convalesced without trouble, rapidly gained weight, and left the hospital in five weeks. March, 1909: Patient is still in good health, and walks ten miles a day.

CAse II.

W. C., aged 67, sorter in the G.P.O. Transferred by Dr. Norman Moore to the care of Mr. Harrison Cripps in November 1908. For the last nine months has been troubled with intermittent diarrhoea, with occasional constipation. For the last few months has had some intermittent pain about the umbilicus. Has lost flesh rapidly. No definite tumour could be felt by palpation until he was put under an anaesthetic when a tumour could be clearly felt situated deeply in the right when a tum

Operation.-November 23rd. On opening the abdomen the caecum was found to be the seat of a new growth involving the valve and a considerable portion of the caecum itself. In the mesenteric attachment two or three glands the size of nuts could be felt, but the finger and thumb could grasp the membrane well beyond them. The whole caecum was removed, with 2 in. of the ileum and 4 in. of the ascending colon, an endto-end anastomosis completing the operation. The patient did well till the third day; he then died quite suddenly without any warning, sitting up in bed and expiring in a few minutes. A the post-mortem examination there was no sign of anything wrong in the abdomen. The anastomosis was perfect, showing no leakage with high water pressure. A careful examination was made for a pulmonary clot, but none was found
CASE III.

Mr. - aged 54, sent to me by Dr. Cayley with the following history: Has always been a most active and healthy man and indeed feels perfectly strong and well at the present moment, with the exception that once or twice lately he has had a sudden sharp pain in the abdomen. The bowels are quite regular. On two occasions in the last three months he has passed blood, dark in colour, and to the amount of a few teaspoonfuls. He also passed one day after a rapid walk "a small mass of flesh the also passed one day after a rapidich did not dissolve in water," On palpation nothing could be felt in the abdomen. Under an an paesthetic by bimanual examination a swelling could be felt high up in the pelvis, but not sufficiently distinct to enable a diagnosis to be made. An exploration was advised.

Operation.-On opening the abdomen by a 5 in. incision in the middle line and introducing the hand, a hard tumour could be felt the size of an egg lying in the pelvis at a level with the summit of the bladder. It was adherent and could not at first be drawn up. However, after separating some slight adhesions with the finger-tips the tumour was freed and suddenly came out of the pelvis right up into the wound. It was then found to be the caecum containing a cancerous growth surrounding the valve. The whole thickness of caecum in about half its diameter being involved. The growth was excised with a very free margin of healthy tissue, the cut bowel being joined end to rend the length of the excised portion being 8 in The patient had no trouble and returned home at the end of a month, and has since remained in perfect health.

\section{Pathology.}

In the vast majority of cases malignant disease in any part of the large intestine is of the adenoid variety. It is essentially a growth starting in the mucous membrane, extending from hence into the submucous and muscular coats. It is only late in the disease that the glands are affected, and eventually the liver and other organs.

Fig. 1 is a section taken from the heaped-up margin of the tumour projecting into the lumen of the bowel. It shows an irregular glandular structure of the involuted type, like Lieberkuhn's follicles. Fig. 2 is a cross-section at point $A$ in Fig. 1 under a higher power. What appears to be the epithelium lining a follicle is, of course, merely an invagination of the epithelium from the growing surface.

If the tumour grows entirely into the lumen of the bowel with a pedicle, it forms an innocent polypus. If, on the other hand, instead of growing free into the bowel cavity, it grows downwards into the muscular coats, it spreads along and through them and becomes malignant.

Microscopically there is no difference in structure between an innocent polypus and malignant disease. It is a question of the direction in which the follicles grow. If growth takes palce from the summit of a follicle, it soon becomes. pedunculated and forms a beautiful tree-like structure, standing out bold and free, like an oak in a park. Such growths may slowly increase to the size of a tennis ball, forming a villous tumour, which may remain innocent for years, and will not recur after removal.

On the other hand, should the growth start from the base of a follicle, it will spread widely into and along the muscular coats and ultimately through them into neighbouring tissues, showing all the characteristics of malignant disease.

Although the great majority of papillomatous and villous tumours remain innocent throughout their career, I have seen and recorded cases in which such growths, after remaining innocent for years, suddenly commence to grow downwards, developing all the characteristics of cancer.

An important fact about cancerous growths in the intestines is that they are less malignant than cancer in many other parts of the body. If left alone, however, I have never known a case in which life has not ultimately been destroyed. On the other hand, if completely removed 
before they have extended through the coats of the bowel, the results are often most satisfactory. J have had quite a fair number of cases of resection of portions of the bowel for cancer which have shown no sign of recurrence after intervals of ten to twenty years.

\section{Symptoms.}

Seeing that success mainly depends on removing the growth before it has perforated through the bowel coats, an early recognition of the symptoms is of the utmost importance. If in the rectum and within reach of the finger the diagnosis is easy, but if high up in the rectum or in any part of the colon the detection of a growth is much more difficult. The higher up the bowel the less are the symptoms; indeed, when high up the colon or in the ileo-caecal valve the onset of complete obstruction may be the first indication of anything seriously wrong.

When low down, as in the rectum, the symptoms are more suggestive. At first the bowels act two or three times a day at odd times. As the disease advances the calls to the closet become very frequent-anything from half a dozen to a dozen times a day. The patient on going to stool does not pass a real motion; more often it is only a few teaspoonfuls of mucus, dark by a mixture of motions and blood. Occasionally there is some bleeding without any motion with

it. This is more com. monly present in an early than in a late stage. The patient is troubled with wind, which he does not like to pass for fear of a mishap into his small clothes. When the sigmoid is affected the symptoms are much the same as in the rectum, but not nearly so pronounced. There is seldom any actual pain at the seat of disease, merely slight colicky discomfort from time to time all over the abdomen. Again, when in the colon, the constant desire to go to the closet is often absent, and there is less discharge. The reason of this is doubtless explained by the different habits of the rectum and colon. The latter objects very little to the accumulation of faeces within it; indeed, this is part of its function. On the other hand, the rectum resents anything being retained, and always has the desire to expel it.

In the 3 cases recorded the general symptoms were slight and not such as to suggest the patients were suffering from so fatal a disease as cancer. In Case III, when the operation showed a considerable mass of growth the opening through which would scarcely admit the little finger, the symptoms were so slight that the patient described himself as feeling in perfect health, with the exception of occasional griping pains, and it was only because he noticed some blood that he sought advice. In any case, when the possibility of a growth in the colon is suspeoted yet nothing can be felt definitely by ordinary palpation, a thorough examination of the abdomen should be made under an anaesthetic. The assistance given by complete relaxation of the muscles in invaluable. In Cases II and III it was only after such an examination that a definite tumour could be felt, and the grounds for an exploratory operation with a view to removal of the growth justifiable.

The Operation.

In resecting portions of the intestine, it seems to me a mistake to remove a $V$-shaped piece of the mesentery as generally recommended. It is obviously important that the blood supply should be as good as possible right up to the cut edges of the bowol. The entire blood supply comes through the mesentery, the vessels anastomosing very freely just before they enter the bowel. No portion of the mesentery can be removed, therefore, without including some of the supply vessels. If instead of removing the $V$-shaped piece the attachment is divided close up to and parallel with the bowel, there is no risk of cutting off the blood supply except to the portion actually removed, and even this is utilized through the anastomosing circulation right up to the cut edges. In sewing the bowel together about one-fourth of its circumference lies between the two layers of the mesentery. It is this portion which requires the most accurate coaptation to get good union, as it is not peritoneal surface to peritoneal surface. To ensure accuracy this part of the circumference should be first united, the needle taking a good grasp of all the coats except the mucous membrane, only just the edges of which are included. The sutures (No. 00 silk) are tied so that the knot lies within the bowel. The remaining circumference of the bowel is united by Lembert's sutures, the knots of which are, of course, tied on the outer surface. After the two rings of the bowel have been united, a few sutures should be passed so as to bring the mesenteric surfaces together and make them continuous with the gut.

As to the after-treatment, it is well for a few days to trust to rectal feeding. The alternate sutures in the abdominal wound can be removed on the ninth day, the remainder three or four days later.

Two of the cases recorded convalesced without any trouble, full motions being passed after the first week, and up to the present time both patients remain in good health. The death of the third patient was not explained by the post. mortem examination. Every thing within the abdominal cavity was found in com. plete order. Not a sign of peritonitis and the junction was firm and completely watertight under high pressure.

These sudden deaths a fow days after abdominal sections must be familiar to every surgeon of large experience. Fortunately they are comparatively rare, but I have had three or four such cases in upwards of 2,000 abdominal sections. The symptoms are all the
same. A patient who is doing perfectly well, with a same. A patient who is doing perfectly well, with a turns an ashy grey colour, with a slight gasping for breath, and falls back dead in a few seconds. It is generally supposed that these sudden attacks are due to a clot in the pulmonary artery, but I can only say, though a careful post-mortem examination was made, no such clot was found in any of my cases, so that some further explanation of these tragic deaths is yet required.

\section{PERFORATED DUODENAL ULCER TREATED BY SUTURE AND GASTRO-ENTEROSTOMY.}

BY W. PAYNTER NOALL, M.S.LOND., F.R.C.S.ENG., YORK.

I was asked to see the following case in consultation by Dr. J. R. Lawther on the evening of January 4th, 1909:

L. W. W., a man aged 44, who was on a visit to York, was suddenly seized on the previous midnight with intense abdominal pain, passing to the right side and top of the right shoulder.

History.

He had washed out his stomach the same day, and as he had taken nothing since, that organ was empty at the onset of the pain. He had eaten little for a week, and had taken only milk 